\section{RESEARCH OF STABILITY OF}

\section{CONTAINERS IN THE COMBINED TRAINS DURING TRANSPORTATION BY RAILROAD FERRY \\ OLEKSIJ FOMIN¹, ALYONA LOVSKA², VACLAV PISTEK³, PAVEL KUCERA ${ }^{3}$}

${ }^{1}$ State University of Infrastructure and Technologies, Kyiv, Ukraine

${ }^{2}$ Ukrainian State University of Railway Transport, Kharkiv, Ukraine

${ }^{3}$ Brno University of Technology, Brno, Czech Republic

DOI: 10.17973/MMSJ.2020_03_2019043 alyonalovskaya.vagons@gmail.com

The article presents results of computational modelling of containers dynamic load during transportation as a part of trains of intermodal transport on a railway ferry. The computational models were developed which account the movement of the container with regard to the frame of the flat wagon while moving of the railway ferry. It was assumed that there is no movement of the flat wagon with regard to the deck, since these movements were limited by fastening means. Attention was also paid to the movement of liquid bulk cargo in the boiler when studied the dynamic load of the tank container. The obtained acceleration rates, as components of the dynamic loads acting on the container, were accounted while determining the containers stability coefficient with regard to the flat wagons. The railway ferry heeling angles which ensure the stability of the containers were determined. The researches will ensure safety of transportation of containers as a part of trains of intermodal transport on a railway ferry, as well as increase the efficiency of operation of intermodal transport in the international transport.

KEYWORDS

Container, bearing structure, dynamic load, strength, railroad ferry transportation

\section{INTRODUCTION}

The development of international economic activity between Eurasian countries enables the commissioning of competitive transport systems. To date the most priority among them is the containers transportation. Containers transportation as a part of intermodal trains was expanded to reduce the time of cargo delivery and transportation costs. These trains can run not only in relation to main-line railways, but also in international rail and water transportations involving railroad ferries (Fig. 1.). It is important to study the load of intermodal trains to ensure the safety of their transportation on railroad ferries, as conditions for the container transportation by sea are significantly different from the conditions of their operation relative to the main-line railways. Therefore, the article focuses on the issue of researching the dynamic load of containers during transportation as a part of intermodal trains on railroad ferries and determining the permissible heeling angles at which the stability of containers is ensured in relation to flat wagons.

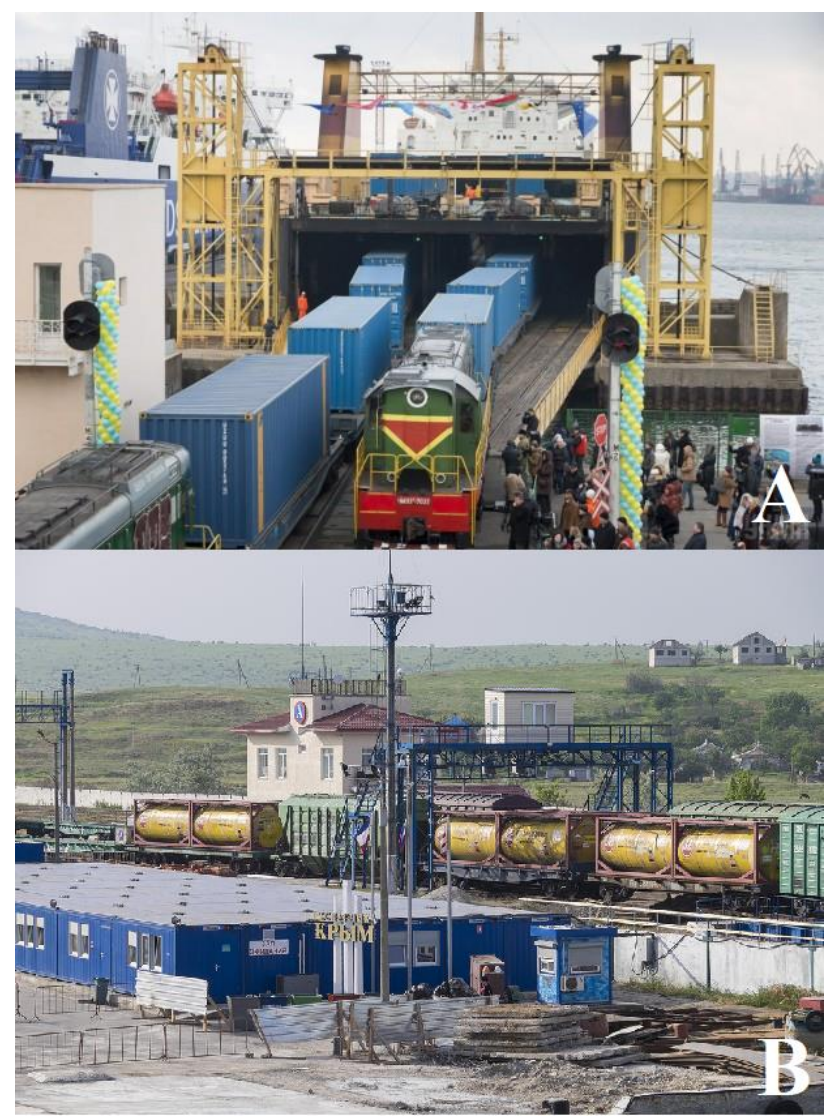

Figure 1. Loading of flat-platform wagons with containers onto railway ferries a) dry cargo containers b) tank containers

\section{ANALYSIS OF RECENT RESEARCH}

Study of the strength of the tank container T11 under operational load conditions is carried out in [Makeev 2018]. The influence of the mesh density on the calculation accuracy of the tank container stress-strain state is analysed, as well as full-scale studies of its strength under shock loads.

Determination of the dynamic load of the tank container at operating load conditions is carried out in [Tiernan 2002]. The obtained values of dynamic loads are taken into account when calculating the strength of a tank container in the software environment Ansys.

For the research it would also be appropriate to be inspired by other articles dealing with the dynamics of movement. [Kostek 2017], [Aleksandrowicz 2017]

The loads that can act on a container during transportation as a part of intermodal trains on railway ferries are not taken into account when calculating strength.

The peculiarities of using simplified methods for measuring the stress-strain state of the body-container of variable volume are given in [Mishuta 2012]. The scheme of loading and test methods of body-containers for transverse and longitudinal swash are proposed in the work.

The peculiarities of invention a container for the transportation of fruit and vegetables are covered in [Ibrahimov 2015]. The requirements for the body-container are given, its construction is proposed and the calculation of the strength using the finite element method is made in the article.

It is important to note that the study of the dynamic load of containers is not carried out in these works, and the determination of strength indicators is carried out taking into account the regulatory values of loads.

An overview of the structure and properties of nanomaterials obtained by isostatic compression is carried out in [Sirota 2013]. 
Possibilities of the implementation of this material in bearing structures of vehicles for ensuring strength under operational load conditions is not carried out in the work.

The peculiarities of testing units of rolling stock on roller stand to determine their dynamic properties under operating conditions is carried out in [Myamlin 2017]. The work does not specify the possibility of using this equipment to determine the dynamic load of containers during transportation on railroad ferries.

Measures concerning the improvement of the automatic coupling draw gear in order to reduce the dynamic load of wagons are highlighted in [Fomin 2018] and [Sapronova 2017]. The results obtained by mathematical modelling are confirmed by computer simulation of the dynamic load of wagons.

Identification of the substantiation peculiarities of the open wagon service life prolongation that have exhausted their normative resource is given in [Fomin 2019a]. The study of the open wagon dynamic load and strength was carried out taking into account the actual wear values of the bearing structure elements of the open wagon in operation.

The task of studying the dynamic load of bearing structures of containers under operating conditions in these works is not stated.

Peculiarities of the improvement of the open wagon bearing structure to ensure the reliability of its fastening on the deck of the railroad ferry are given in [Fomin 2019b] and [Lovskaya 2015]. The proposed technical solutions are confirmed by calculations on strength; the results are given in the article.

The problems of determining the dynamic loading of containers during transportation as a part of intermodal trains on railroad ferries are not considered in the work.

\section{CREATING THE COMPUTATIONAL MODEL}

The aim of the research was to create a computational model describing the peculiarities on dynamic load of a container placed on a flat wagon during transportation by a railroad ferry. To achieve this goal, the following tasks were defined:

- To develop a mathematical model for determining the dynamic load of a container placed on a flat wagon during transportation by a railroad ferry;

- To determine the stability coefficient of the container placed on a flat wagon during transportation by railroad ferry;

- To develop a mathematical model for determining the dynamic load of a tank container placed on a flat wagon during transportation by a railroad ferry;

- To determine the stability coefficient of a tank container placed on a flat wagon during transportation by railroad ferry.

The computational model was developed to determine the dynamic load of the container during transportation as a part of intermodal train on the railroad ferry. This model accounts the angular movements of the elements of the system ("railroad ferry - container") around the longitudinal axis (roll), as a case of the greatest load of the bearing structure of the container during transportation by railroad ferry, as well as ensuring its stability with respect to the frame of the flat wagon. The model does not account the movements of the flat wagon. That is, it is assumed that they are limited by fastening means relative to the deck. The layout of platform wagons with containers on a railway ferry for angular movements relative to the longitudinal axis is shown in Fig. 2 and the following equations are used
$\left(\frac{D}{12 g}\left(B^{2}+4 z_{g}^{2}\right)\right) \ddot{\theta}_{1}+\left(\Lambda_{\theta} \frac{B}{2}\right) \dot{\theta}_{1}=p_{F B}^{\prime} \frac{h}{2}+\Lambda_{\theta} \frac{B}{2} F(t)$,

$I_{K}^{\theta} \ddot{\theta}_{2}=p_{K}^{\prime} \frac{h_{K}}{2}+M_{K}^{D}$,

where $\theta_{1}$ is the generalized coordinate which corresponds to the angular displacement around the longitudinal axis of a railroad ferry, $\theta_{2}$ is a generalized coordinate which corresponds to the angular displacement around the longitudinal axis of the container. The coordinate system origin is located in the railroad ferry centre of mass.

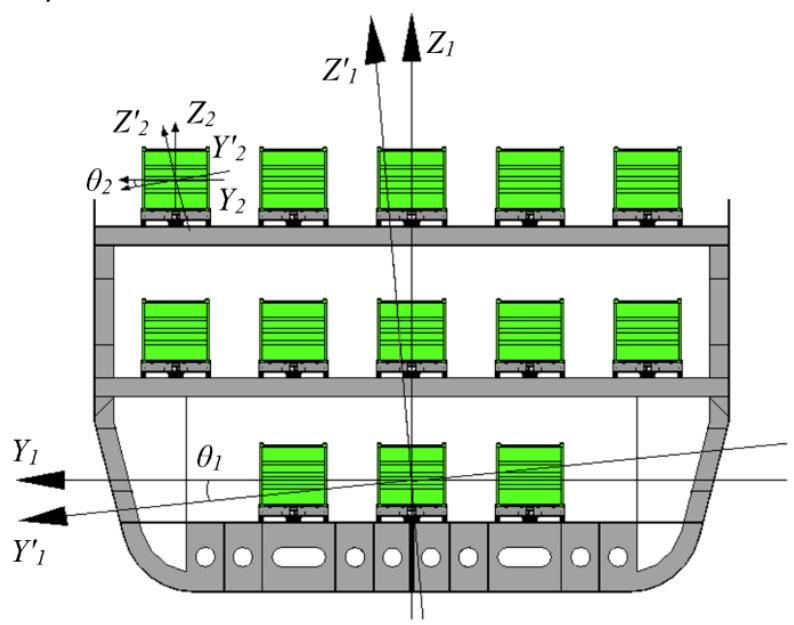

Figure 2. Layout of platform wagons with containers on a railway ferry

\section{For railroad ferry:}

$D$ is the weight displacement, $B$ is the width; $h$ is the height of the board, $\Lambda_{\theta}$ is coefficient of resistance to fluctuations, $z_{g}$ is coordinate of the gravity centre, $p_{F B}^{\prime}$ is the wind load on the uncovered projection, $F(t)$ is the law of force effect that moves a railroad ferry with wagons located on its decks.

\section{For the container:}

$I_{K}{ }^{\theta}$ is the moment of inertia of the container, $h_{k}$ is the height of the side surface of the container, $p^{\prime}{ }_{K}$ is wind load on the side of the container, $M_{K}{ }^{D}$ is force moment that occurs between the container and the deck at angular movements relative to the longitudinal axis.

The perturbing effect was described as a trochoidal motion of the sea wave [Lugovskij, 1976]

$$
\begin{aligned}
& x=a+R e^{k b} \sin (k a+\omega t) \\
& z=b-R e^{k b} \cos (k a+\omega t)
\end{aligned}
$$

where $a$ and $b$ are the horizontal and vertical coordinates of the centre of the path along which the body that currently has the $x$ and $z$ coordinates is fighting, $R$ is the radius of the path along which the rotation occurs, $\omega$ is the frequency of the sea wave, $k$ is the frequency of the wave path. The frequency of the disturbance is determined taking into account the course angle of the wave with respect to the hull of the railway ferry

$\omega=\frac{2 \pi v}{k_{\lambda} L \cos \chi}$

where $v$ - railway ferry speed, $k_{\lambda}$ - coefficient, which depends on the shape of the contours of the vessel, $\chi$ - course angle of the wave with respect to the hull.

The coefficient of resistance to movement of the railway ferry was determined by the formula 
$\Lambda_{\theta}=\int_{-L / 2}^{L / 2} \rho \omega T^{2} \Lambda_{i} d t$

where $\rho$ - sea water density, $\omega$ - ship oscillation frequency, $T$ ship oscillation period, $\Lambda_{i}$ - dimensionless damping coefficient, which is determined by the graphic dependencies of the reference literature, in accordance with the technical characteristics of the railway ferry, $L$ - ship length [Blagoveshchensky 1975].

The impact of sea waves on the hull of a railroad ferry with wagons placed on its board was not taken into account. The trochoidal law of the moving action (of sea wave) on the railroad ferry with wagons located on its decks and the dissipative component that occurs during the fluctuations of the railroad ferry in the conditions of the sea disturbance were taken in account during developing the model, as well as the wave-tocourse angle in relation to the railroad ferry hull $\left(\chi=0^{\circ}-180^{\circ}\right)$ and the wind load acting on the uncovered projection of the railroad ferry, the flat wagon located on the upper deck and containers.

It is assumed that the container has its own degree of freedom to the time when the vertical wall of the fitting will lean against the fitting.

The research has been conducted relating to the ferry "Geroi Shipki", which moves along the Black Sea water area. The model 13-4012 was chosen as the basic model of the flat wagon and the model of $1 \mathrm{CC}$ with a gross mass of 24 tons was chosen as a basic model of the container. The hydrometeorological characteristics of the Black Sea area are determined according to the data given in [Davidan 1974]. The speed of the railroad ferry was assumed to be equal to its operating speed of 18.6 knots $(9.57 \mathrm{~m} / \mathrm{s})$ and was accounted as permanent when moving along the sea area. It has been taken into account that the platform wagon is fixed relative to the deck according to a typical scheme using chain ties with lanyards and stop-jacks. In order to avoid rolling of wagons with respect to rails, brake shoes are installed under the surface of the wheels, and in the longitudinal direction, the last wagons in the trailers are connected with dead ends. In addition, for the purpose of braking the wheelsets, the braking system of the wagons is connected to the special arms of the system for supplying compressed air (Fig. 3).

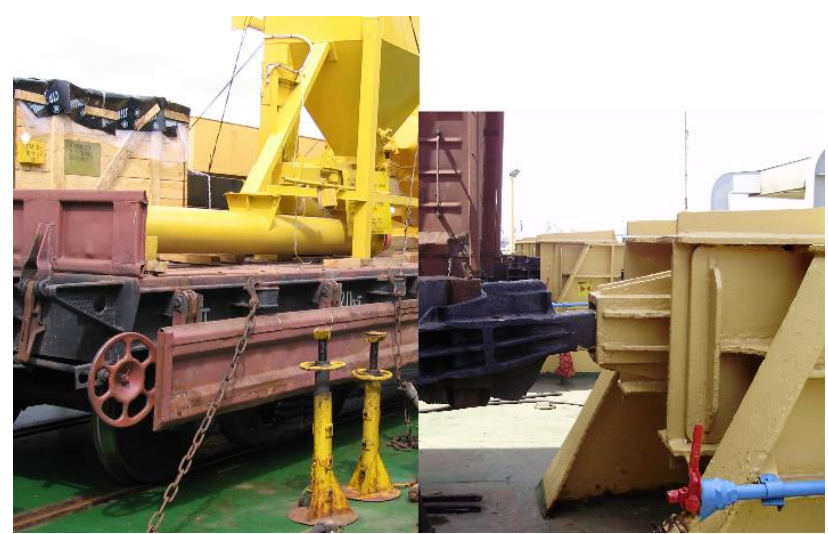

Figure 3. Securing the flat wagon on the deck of the railway ferry

Differential equations of motion were solved applying the programming environment Mathcad [Kiryanov 2006] and [Kondratiev 2019] by using the Runge-Kutta method.

It was established that the maximum acceleration value acting on the container is about $2.5 \mathrm{~m} / \mathrm{s}^{2}$ and occurs at the wave-tocourse angles of $60 \mathrm{deg}$ and $120 \mathrm{deg}$ in relation to the hull of the railroad ferry. The total value of the acceleration acting on the container is $4.57 \mathrm{~m} / \mathrm{s}^{2}(0.47 \mathrm{~g})$ taking into account the horizontal component of acceleration of free fall, caused by the angle of the railway train ferry (Fig. 4). At the same time, the estimated heeling angle of the railroad ferry at a static wind action on the uncovered projection was $12.2 \mathrm{deg}$

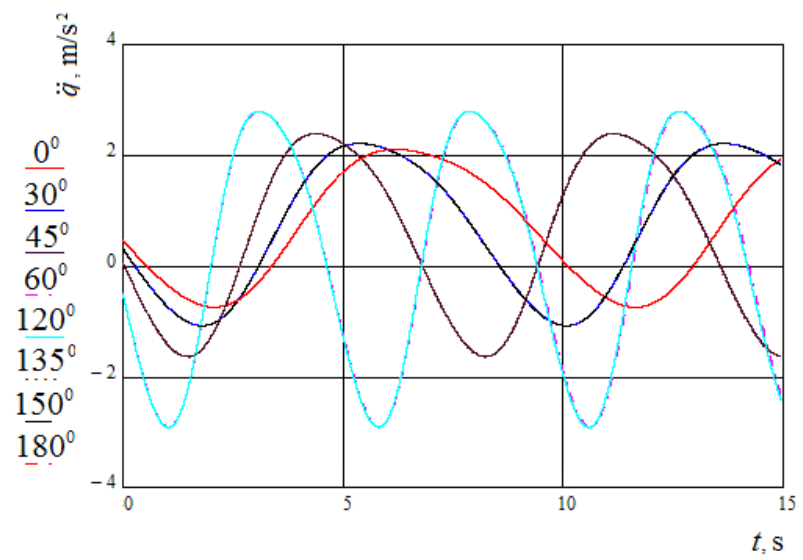

Figure 4. Accelerations that apply to a container placed on a flat wagon when transported by rail ferry

Moreover, each colour of the curve in Fig. 4 corresponds to the acceleration value obtained for a certain directional angle of the wave with respect to the hull of the railway ferry (the values of the angles are shown on the side of the ordinate axis).

Studies of the equilibrium stability coefficient were performed at angular movements of the railroad ferry relative to the longitudinal axis in order to assess the stability of containers in relation to the frame of the flat wagon.

The accelerations were taken into account in determining the overturning moment. These accelerations were calculated using mathematical modelling and are the components of the dynamic load acting on the container.

To ensure the stability of the container's equilibrium with regard to the frame of the flat wagon, the following condition must be fulfilled:

$k_{c}=\frac{M_{r e s t}}{M_{o v}} \geq 1$,

where $M_{\text {rest }}$ is the magnitude of the restoring moment, $M_{o v}$ is the magnitude of the overturning moment.

$M_{o v}=p_{K}^{\prime} \frac{h_{K}}{2}+M_{g}\left(g \sin \theta_{1}+\ddot{\theta}_{2}\right) \frac{h_{K}}{2}$,

$M_{\text {rest }}=P_{g} \frac{B_{K}}{2} \cos \theta_{1}+n_{f}\left(M_{g}\left(g \sin \theta_{1}+\ddot{\theta}_{2}\right) \frac{h_{f}}{2}\right.$,

where $M_{g}$ - the gross mass of the container, $P_{g}$ - the gross weight of the container, $B_{K}$-the width of the container, $n_{f}$ - the number of fitting pieces which support the container at angular movements relative to the longitudinal axis, $h_{f}$ is height of the fitting piece.

The calculation scheme of a container placed on a flat wagon during transportation on a railroad ferry is shown in Fig. 5.

The results of the calculation in the form of characteristic curve are shown in Fig. 6. In this case, the threshold of stability is established when the magnitudes of the restoring and overturning moments are equal. The stability curve is indicated by blue, the trend line (black colour) is described by the equation

$k_{c}=0.0055 \theta_{1}^{2}-0.4006 \theta_{1}+8.014$. 


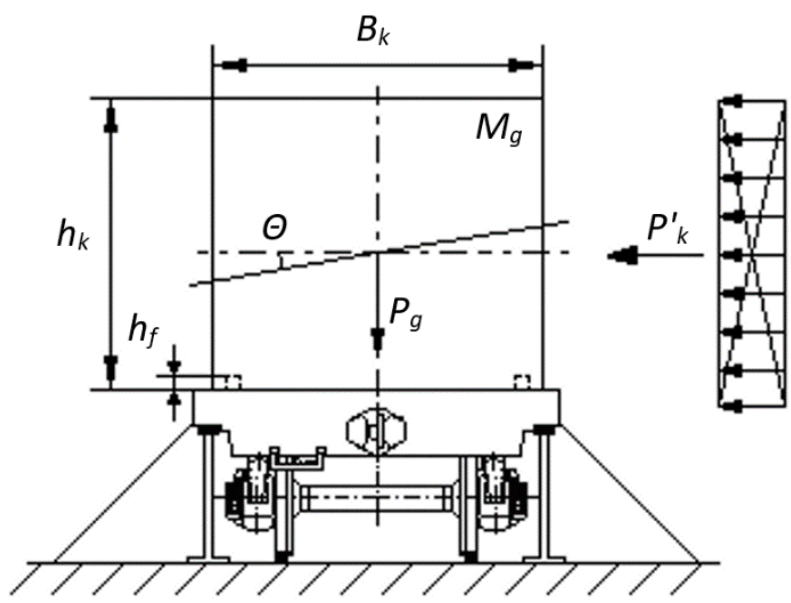

Figure 5. The calculation scheme of the container placed on a flat wagon when transported by railroad ferry

The conducted studies allowed us to conclude that the stability of the container under this calculation scheme was provided at the corners of the railroad ferry up to $30 \mathrm{deg}$ taking into account the possible movements of container fittings with respect to the fitting of the flat wagon.

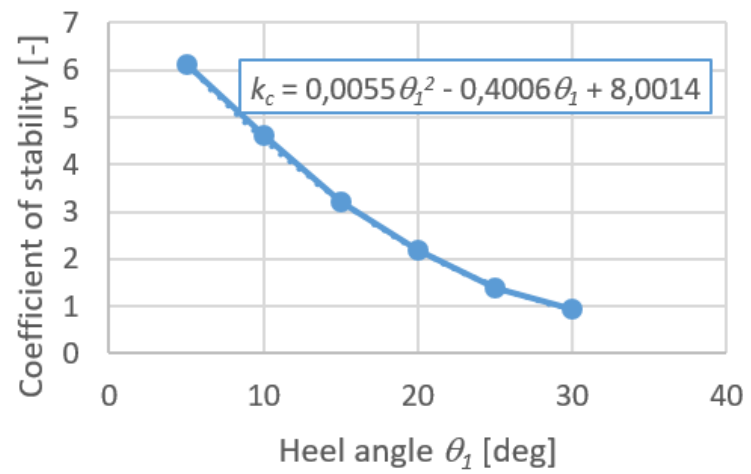

- stability curve $\quad$........ trend line

Figure 6. Dependence of the stability coefficient of the container placed on a flat wagon from the heeling angle of the railroad ferry

Mathematical model (11-13) is developed to determine the dynamic load of the tank container during transportation as a part of intermodal train on the railroad ferry. This model which into account the movement of the system "railroad ferry - tank container - liquid bulk cargo" at angular movements around the longitudinal axis. The layout of platform wagons with tank containers on a railway ferry is shown in Fig. 7 . The model takes into account that the flat wagon on which the tank container is placed rigidly fixed to the deck of the railroad ferry and moves along with it.

$\left(\frac{D}{12 g}\left(B^{2}+4 z_{g}^{2}\right)\right) \ddot{\theta}_{1}+\left(\Lambda_{\theta} \frac{B}{2}\right) \dot{\theta}_{1}=p_{F B}^{\prime} \frac{h}{2}+\Lambda_{\theta} \frac{B}{2} F(t)$,

$\left(I_{\theta i}+\sum_{j=1}^{k} m_{i j} c_{i j}^{2}\right) \ddot{\theta}_{2}+\sum_{j=1}^{k} m_{i j} c_{i j} l_{i j} \ddot{\theta}_{3}-g\left(m_{i} z_{c i}+\sum_{j=1}^{k} m_{i j} c_{i j}\right) \theta_{2}=p_{K}^{\prime} \frac{h_{K}}{2}$,

$I_{i j} \ddot{\theta}_{3}-m_{i j} c_{i j} l_{i j} \ddot{\theta}_{2}+g m_{i j} l_{i j} \theta_{3}=0$,

where $\theta_{1}, \theta_{2}, \theta_{3}$ are generalized coordinates corresponding to the angular movement around the longitudinal axis, respectively, the railway ferry, the tank container and the liquid bulk cargo. The coordinate system origin is located in the railroad ferry centre of mass.

The constituents included in the equation of motion the railroad ferry are identical to those described in the system (1-2).

For tank-container with liquid bulk cargo:

$l_{i j}$ is the moment of inertia of the pendulum, $m_{i j}$ is the weight of the $j$-th pendulum in the $i$-th tank container, $c_{i j}$ is the distance from the plane $z_{i}=0$ to the point of fixing the $j$-th pendulum in the $i$-th tank container, $l_{i j}$ is the length of the $j$-th pendulum, $l_{e}$ is the reduced moment of inertia of the $i$-th tank container and liquid bulk cargo that does not participate in the movement relative to the tank, $z_{c i}$ is height of the gravity centre of the tank container, $m_{i}$ is the mass of the body, which is equivalent to the second tank container with a part of the liquid bulk cargo that does not take part in the movement relative to the tank, $F_{k}$ is the force moment between the tank container and the flat wagon. The description of the process of movements of the tank container with liquid bulk cargo was carried out according to the method shown in [Bogomaz 1992].

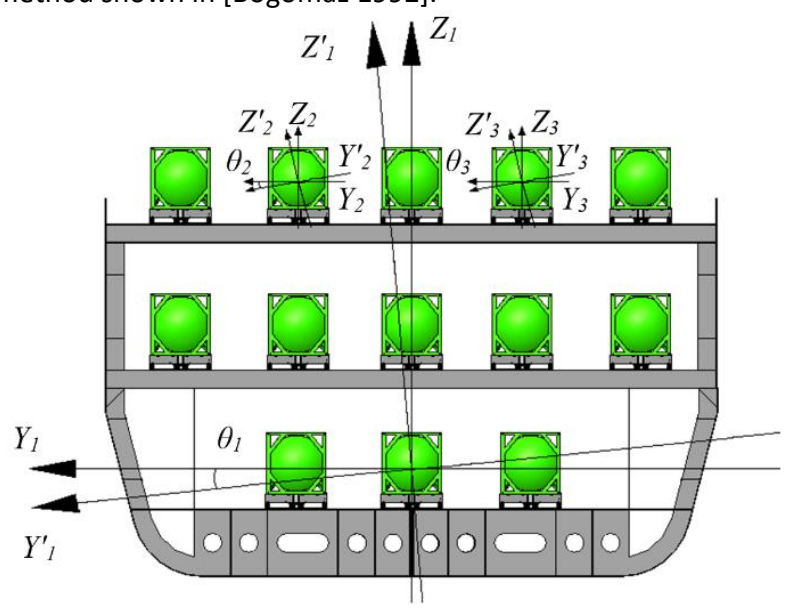

Figure 7. Layout of flat wagons with tank containers on a railway ferry

Petroleum is accepted as liquid bulk cargo. Determination of the hydrodynamic characteristics of the liquid bulk cargo was carried out taking into account the maximum permissible loading of the tank container boiler - $95 \%$ of its total capacity in accordance with [Commonwealth of Railways 2011]. The movement of liquid bulk cargo was described by a set of mathematical pendulums [Bogomaz 1992].

The results of the studies allowed us to conclude that the maximum accelerations that act on the tank container are about $3.8 \mathrm{~m} / \mathrm{s}^{2}$ (Fig. 8). The total acceleration value will be $5.97 \mathrm{~m} / \mathrm{s} 2$ $(0.61 \mathrm{~g})$ taking into account the horizontal component of the acceleration of free fall due to the angle of inclination of the railroad ferry. The graphic dependence of the stability coefficient of the tank container relative to the frame of the flat wagon from the heeling angle of the railroad ferry was developed (Fig. 9) based on the calculations carried out. The stability curve is marked with blue, and the trend line is black. The trend line equation is as follows:

$k_{c}=2.7286 e^{-0.07 \theta_{1}}$

The calculation scheme of the tank container is assumed to be identical to that considered for the dry cargo container. It can be seen from Fig. 9 that the stability of the tank container relative to the frame of the flat wagon, taking into account the given calculating scheme, is provided at the heeling angles of the railroad to $12 \mathrm{deg}$. 


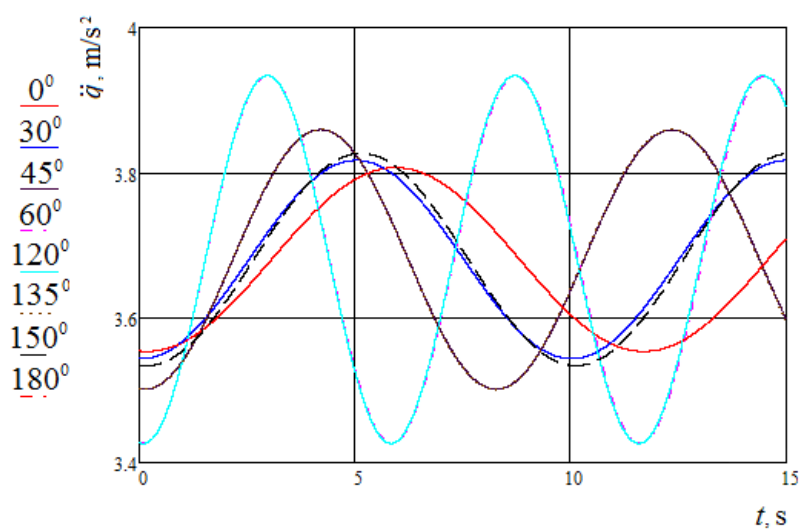

Figure 8. Accelerations that apply to a tank container placed on a flat wagon when transported by railroad ferry

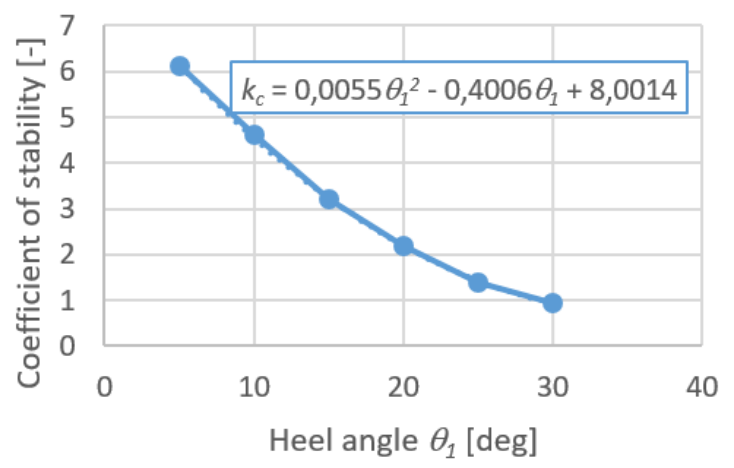

- stability curve $\quad . . . .$. trend line

Figure 9. Dependence of the stability coefficient of the tank container placed on a flat wagon from the heeling angle of the railroad ferry

Consequently, the movements of liquid bulk cargo taking into account the assumptions made when simulated provides the increasing dynamic load of the container of $40 \%$.

\section{CONCLUSIONS}

Based on the conducted research, it is possible to draw the following conclusions:

A computational model for determining the dynamic load of a container placed on a flat wagon during transportation by a railroad ferry was developed. It was stated that the maximum acceleration value acting on the container is about $2.5 \mathrm{~m} / \mathrm{s}^{2}$ and occurs at the wave-to-course angles in relation to the hull of the railroad ferry of $60 \mathrm{deg}$ and $120 \mathrm{deg}$. The total value of the acceleration acting on the container, taking into account the horizontal component of acceleration of free fall is $4.57 \mathrm{~m} / \mathrm{s}^{2}$ (0.47 g).

The stability coefficient of the container placed on the flat wagon during transportation by a railroad ferry was determined. Taking into account possible movements of container fittings with respect to fittings of the flat wagon, the container stability is provided at the railroad ferry heeling angle up to $30 \mathrm{deg}$.

A computational model for determining the dynamic load of a tank container placed on a flat wagon during transportation by a railway ferry was developed. In this case, the maximum accelerations that act on the tank container are about $3.8 \mathrm{~m} / \mathrm{s}^{2}$. Taking into account the horizontal component of acceleration of free fall due to the angle of inclination of the railroad ferry, the total acceleration value is $5.97 \mathrm{~m} / \mathrm{s}^{2}(0.61 \mathrm{~g})$.
The stability coefficient of the tank container placed on the flat wagon during transportation by a railroad ferry was determined. It was stated that the stability of the tank-container relative to the frame of the flat wagon is provided at the railroad ferry heeling angles up to $12 \mathrm{deg}$.

The conducted researches will provide the development of recommendations on the safety of container transportation on railroad ferries by sea, clarification of existing regulatory documentation on the design and calculation of vehicles for transportation on railroad ferries [DSTU 7598:2014], [GOST 33211-2014] and [EN 12663-2 2010], as well as increase the efficiency of intermodal transport operations.

\section{ACKNOWLEDGMENTS}

The research was made within the taxpayer-funded research "Innovative approaches in designing resource-saving car structures with consideration of refined dynamic loading and functional-adaptive flash-concepts".

The authors gratefully acknowledge funding from the Specific research on BUT FSI-S-20-6267.

\section{REFERENCES}

[Aleksandrowic 2017] Aleksandrowicz, P. Verifying a truck collision applying the SDC method. 58th International Conference of Machine Design Departments 2017, Prague, 2017, pp. 14-19

[Blagoveshchensky 1975] Blagoveshchensky, S.N. and Kholodilin, A.N. Handbook on the statics and dynamics of the ship. Leningrad: Shipbuilding, 1975. ISBN MИB 14-6H2-26012019-93 (in Russian)

[Bogomaz 1992] Bogomaz, G.l., et al. Loading capacity of tank containers located on a railway platform during impacts into the automatic coupler. Collection of scientific papers "Dynamics and control of motion of mechanical systems", May 1992, pp 87-95. ISBN 512-002792-X (in Russian)

[Commonwealth of Railways 2011] Rules for the transport of dangerous goods. To the agreement on international railway freight traffic. Volume $3 /$ Commonwealth of Railways, 2011. 531 s. (in Russian).

[Davidan 1974] Davidan, I.N., Lopatuhin, L. I. and Rozhkov, V. A. Wind and waves in the oceans and seas. Leningrad: Transport, 1974. (in Russian)

[DSTU 7598:2014] DSTU 7598:2014. Freight wagons. General requirements for the calculations and design of new and upgraded $1520 \mathrm{~mm}$ (non-self-propelled) rail wagons, 2015. (in Ukrainian)

[EN 12663-2 2010] EN 12663-2. Railway applications - structural requirements of railway vehicle bodies - Part 2: Freight wagons, 2010.

[Fomin 2018] Oleksij Fomin, Juraj Gerlici, Alyona Lovskaya, Kateryna Kravchenko, Pavlo Prokopenko, Anna Fomina and Vladimír Hauser. MATEC Web of Conferences, November 2018, Vol.235. No.3, pp 1-5. elSSN 2261-236X

[Fomin 2019a] Fomin, O., et al. Determining strength indicators for the bearing structure of a covered wagon's body made from round pipes when transported by a railroad ferry. Eastern-European journal of enterprise technologies, January 2019, Vol.7, Issue 1 (97). pp. 33-40. ISSN 1729-3774

[Fomin 2019b] Fomin, O., et al. Durability Determination of the Bearing Structure of an Open Freight Wagon Body Made of Round Pipes during its Transportation on 
the Railway Ferry. Communications-Scientific letters of the University of Zilina, January 2019, Vol. 21, No.1, pp 28-34. ISSN 1335-4205

[GOST 33211-2014] GOST 33211-2014. Freight wagons. Strength and Dynamic Requirements, 2016. (in Russian)

[Ibrahimov 2015] Ibrahimov, N. N., et al. Development of the design of a container for transportation of fruits and vegetables. Young scientist, October 2015, No.21 (101), pp 168-173. ISSN 2072-0297 (in Russian)

[Kiryanov 2006] Kiryanov, D.V. Mathcad 13. Petersburg: BHV, 2006. ISBN 5-94157-849-0 (in Russian)

[Kondratiev 2019] Kondratiev, A.V. et al. Relationships between the ultimate strengths of polymer composites in static bending, compression, and tension, Mechanics of Composite Materials, May 2019, Vol.52, No.2. pp 259-266. ISSN 0191-5665

[Kostek 2017] Kostek, R. and Aleksandrowicz, P. Simulation of car collision with an impact block. 11th International Congress of Automotive and Transport Engineering 2017, Pitesti, 2017, doi: 10.1088/1757899X/252/1/012008

[Lovskaya 2015] Lovskaya, A. A. Peculiarities of computer modelling of strength of body bearing construction of gondola car during transportation by ferry-bridge. Metallurgical and Mining Industry, January 2015, No.1. pp 49-54. ISSN 2076-0507

[Lugovskij 1976] Lugovskij, V.V. Sea Dynamics: Selected issues related to the teaching of seaworthiness of the ship. Textbook for technical colleges in the specialty "Hydroaerodynamics", Leningrad: Shipbuilding, 1976. (in Russian)
[Makeev 2018] Makeev, S. V. and Buylenkov, P. M. Features of the calculation of the stress-strain state of the container tank, taking into account the actual loading into operation. XIV International Scientific and Technical Conference "SCIENCE - EDUCATION PRODUCTION: Experience and Development Prospects", dedicated to the memory of Doctor of Technical Sciences, Professor E. G. Zudov, February 2018, Ural Federal University, pp 174-184. ISSN 9785-9544-0089-2 (in Russian)

[Mishuta 2012] Mishuta, D. V., et al. Simplified methods for measuring the stress-strain state of a container body of variable volume. Devices and measurement methods, December 2012, No.2 (5), pp 100-103. ISSN 2220-9506 (in Russian)

[Myamlin 2017] Myamlin, S., et al. Testing of Railway Vehicles Using Roller Rigs. Procedia Engineering, May 2017, Vol.187, pp. 688-695. ISSN 1877-7058

[Sapronova 2017] Sapronova, S., et al. Research on the safety factor against derailment of railway vehicles. Eastern-European Journal of Enterprise Technologies, December 2017, Vol.6, Issue 7 (90). pp. 19-25. ISSN 1729-3774

[Sirota 2013] Sirota, V.V., et al. Structure and properties of nanoporous ceramic $\mathrm{TiO} 2$ obtained by isostatic pressing. Glass and Ceramics, January 2013, Vol.69, No.9-10., pp 342-345. ISSN 0361-7610

[Tiernan 2002] Tiernan, S., et al. Dynamic fea modelling of iso tank. Journal of materials processing technology, June 2002, No.124 (1), pp 126-132. ISSN 0924-0136

\section{CONTACTS:}

Alyona Lovska, Ph.D.

Ukrainian State University of Railway Transport, Department of Wagons

Feierbakh sq., 7, 61050, Kharkiv, Ukraine

+38057 73010 35, alyonalovskaya.vagons@gmail.com 